\title{
Erratum to: The benefits of anti-corruption programming: implications for low to lower middle income countries
}

\author{
Bertram I. Spector ${ }^{1}$
}

\section{Erratum to: Crime Law Soc Change DOI 10.1007/s10611-016-9606-x}

The two tables in the Annex (Tables 6 and 7) are not displayed correctly. For each variable row, there are three rows of statistics that should be labeled: "Pearson r", "sig. (2-tailed)"; and "N". The labels have been INCORRECTLY grouped together in a paragraph, not put on separate rows

Tables 6 and 7 are already corrected in the published version of the article.

The online version of the original article can be found at doi: http://dx.doi.org/10.1007/s10611-016-9606-x.

Bertram I. Spector

bspector@msi-inc.com

1 Management Systems International, 200 12th Street South, Arlington, VA 22202, USA 